\title{
Ortaokul Öğrencileri için Voleybol Tutum Ölçeğinin Geliştirilmesi*
}

\author{
Hulusi BÖKE ${ }^{1+}$ (D), Mehmet GÜLL ̈̈ ${ }^{2}$ \\ ${ }^{1}$ Yaşar Öncan Ortaokulu, Malatya. \\ 2 İnönü Üniversitesi, Malatya.
}

Orijinal Makale

Gönderi Tarihi: 04.07.2020
Kabul Tarihi: 18.09.2020
DOI: 10.25307/jssr.764005

Online Yayın Tarihi: 31.12.2020

\section{Öz}

$\mathrm{Bu}$ araştırmada, öğrencilerin voleybola karşı tutumlarını ölçen bir ölçek geliştirme amaçlanmıştır. 30 ortaokul öğrencisine voleybol ile ilgili kompozisyon yazdırılarak betimsel analiz yapılmıştır. Öğrencilere kompozisyonlar yazdırılarak alan yazındaki kaynaklar taranmış ve 60 maddelik ölçek taslağı oluşturulmuştur. Ölçek taslağı alanında uzman 8 öğretim üyesine sunulmuştur. Ölçek taslağı uygulaması sonucunda toplam 528 (277'i kız ve 251'i erkek) öğrencinin eksiksiz ve hatasız bir şekilde doldurduğu ölçek formu bilgisayar programına yüklenmiştir. İlk olarak olumsuz sorular ters çevrilerek istatistik programına kaydedilmiştir. Kaydedilen verileri test etmek için Açıklayıcı ve Doğrulayıcı faktör analizi (AFA ve DFA) yöntemleri uygulanmıştır. Açıklayıcı faktör analizi çerçevesinde başvurulan Kaiser-Meyer-Olkin (KMO) puanı 0,96 ve Bartlett Test sonucu anlamlı ( $\mathrm{p}<0,01$ ) bulunmuştur. Analizde maddeler tek faktörde toplanmış ve faktör yük değeri 0,50 ve üzeri olan 18 madde seçilmiştir. Maddelerin faktör yüklerinin 0,54 ve 0,74 arasında değişim gösterdiği belirlenmiştir. Tek faktörün, \%44,97 oranında bir varyansı açıkladığ görülmüştür. Madde-toplam korelasyonunda, maddelerin 0,48 ile 0,69 arasında korelasyon katsayısına sahip oldukları görülmüştür. AFA neticesinde ölçekte bulunan 18 madde Lisrel 8.8 istatistik paket programına DFA yapmak amacıyla yüklenmiştir. DFA'ya yönelik uyum indekslerinin gerekli şartları sağladığı görülmüştür. Böylece, 16 maddesi bulunan ölçek, AFA ile DFA neticesinde geçerliliği karşılanmış bir ölçektir. Aynı şekilde, ölçeğin iç tutarlılığı (Cronbach Alfa) 0,92; yap1 güvenirliliği 0,92; açıklanan varyansı 0,43 olan güvenilirliği karşılanmış bir ölçektir. Ortaokul öğrencilerine yönelik geliştirilen voleybol tutum ölçeği, geçerli ve güvenilir bir ölçektir. Son hali ile ölçek olumlu 16 maddeden oluşmaktadır.

Anahtar Kelimeler: Voleybol, Tutum, Ölçek, Geçerlik, Güvenirlik.

\section{Development of Volleyball Attitude Scale for Secondary School Students}

\begin{abstract}
In this study, it was aimed to develop a scale measuring students' attitudes towards volleyball. Descriptive analysis was carried out by writing composition about volleyball to 30 secondary school students. By writing the compositions to the students, the sources in the literature were scanned and a 60-item scale draft was created. The draft of the scale was presented to 8 faculty members who are experts in their field. As a result of the scale draft application, a total of 528 (277 female and 251 male) students filled in the form of the scale was uploaded into the computer program. First, negative questions were reversed and recorded in the statistics program. Explanatory and Confirmatory factor analysis methods were applied to test the recorded data. Kaiser-Meyer-Olkin score applied within the framework of explanatory factor analysis was 0.96 and Bartlett test result was found to be significant $(\mathrm{p}<0.01)$. In the analysis, the items were collected in one factor and 18 items with a factor load value of 0.50 and above were selected. It was determined that the factor loads of the items varied between 0.54 and 0.74 . It was observed that the single factor explained a variance of $44.97 \%$. In the item-total correlation, it was observed that the items had a correlation coefficient between 0.48 and 0.69. As a result of EFA, the 18 items in the scale were loaded into the Lisrel 8.8 statistical package program in order to perform CFA. It is seen that the compliance indexes for DFA provide the necessary conditions. Thus, the scale with 16 items is a valid scale as a result of AFA and DFA. Likewise, the internal consistency of the scale (Cronbach Alfa) 0.92; building reliability 0,92; It is a reliable scale with the explained variance of 0.43 . The volleyball attitude scale developed for secondary school students is a valid and reliable scale. In its final form, the scale consists of 16 positive items.
\end{abstract}

Keywords: Volleyball, Attitude, Scale, Validity, Reliability.

*Bu makale İnönü Üniversitesi Sağlık Bilimleri Enstitüsü'nde hazırlanan Yüksek Lisans tezinden türetilmiştir. Ayrıca, 23-26 Kasım 2017 tarihinde düzenlenen "Dünya Spor Bilimleri Araştırmaları" kongresinde poster bildiri olarak sunulmuştur. † Sorumlu yazar: Dr. Hulusi BÖKE, E-posta: yakamoz8386@gmail.com 


\section{GíRiş}

Tutumların işlevleri hakkındaki teoriler üzerine yapılan çalışmalar otuz yıl öncesine dayanmaktadır (Katz ve Stotland, 1959; Katz, 1960; Kelman, 1958, 1961; Smith, Bruner, \& White, 1956). Tutum bir duruma, kişiye veya faaliyete karşı özel bir duygu, kişinin algısal dünyasının bir yönüyle sürekli bir motivasyon, heyecan, algılama ve öğrenme süreçleri organizasyonu olarak ifade edilir (Krech ve Crutchfield, 1980; Safrit ve Wood, 1995).

Klausmeier, Goodwin, Prasch ve Goodson (1966) tutumu bir fikre, nesneye veya kişiye olumlu ya da olumsuz tepki verme eğiliminin duygusal düzeyi olarak tanımlar. Hilgard, Atkinson ve Atkinson'a (1971) göre tutum, belirli nesneler, kavramlar ve durumlardan yakınlaşma veya uzaklaşma ile bunlara karşı belirli bir yönde hareket etmeye hazır olma anlamına gelir. Franzoi (2003) tutumu, kişinin herhangi bir nesneyi olumlu ya da olumsuz anlamda değerlendirmesi olarak tanımlamıştır. Ayrıca bir bireyin sosyal çevresi ve yaşantısı içerisinde bulunan belirli olay ve olgulara yönelik geliştirmiş ve gerçekleştirmiş olduğu psikolojik örgütlenmenin, kendisinin davranışlarına tesir eden bölümü şeklinde ifade edilmektedir (Güvenç, 1976). Smith, Bruner ve White, (1956) tutumların benlik ve diğer ilişkilere aracıllk ettiğini, kişinin kimliğini oluşturduğunu (sosyal uyum işlevi) açıklamaktadır. Katz (1960) ise tutumların kişinin merkez değerleri ile benlik kavramını sembolize ve ifade ettiğini belirtmiştir (değerifade edici işlev). Diğer taraftan Carlson (1994) tutumun kültür, toplum ve okulla bağlantıll faktörlerden etkilendiğini belirtmektedir.

Okul beden eğitimi derslerinin öğrencilerin zihinsel, sosyal, ruhsal ve fiziksel gelişimlerini desteklemek gibi bazı hedefleri olduğu bilinmektedir (Strand \& Scantling, 1994). Öğrencilerin tutumları üzerinde olumlu ve olumsuz etkisi olan faktörlerin belirlenmesi, onların duygularını anlamada ve beden eğitimi alanında başarıya ulaşmalarında kilit bir rol oynar (Aicinena, 1991; Silverman ve Subramaniam, 1999). Böylelikle öğrencilerin voleybola karşı olumlu tutumları, derslere gönülden katılmalarını ve yakın çevrelerindeki etkinlikleri değerlendirmelerini sağlayacaktır. Buna ek olarak, kişi bu etkinlikler sırasında iyi bir voleybol oyuncusu olma firsatına sahip olacaktır. Ayrıca bu faaliyetlerin devamında kişi iyi bir voleybol sporcusu olma firsatını yakalamış olacaktır. Okullar, çocukların ve gençlerin belirli bir program dahilinde fiziksel aktivite ve spora katıldığı yerdir. Okul çağındaki çocuklar ders dışı faaliyetlerinin yanı sıra beden eğitimi ve spor dersleri ile fiziksel aktivite yapma şansı bulurlar (Uğraş ve Serbes, 2019). Ortaokul öğrencileri yaş ortalamasının 11-14 olduğu düşünüldüğünde; ergenlik döneminin (12-21 yaş arası) bu dönemi kapsadığı ve bu dönemin tutumların şekillendiği bir dönem olduğu söylenebilir (Güllü ve Güçlü, 2009). Beden eğitimi dersleri ile kişiler sağlikla ilişkili fiziksel uygunluk, sağlıklı bir vücut kompozisyonu, esneklik, aerobik kapasite, yenilik ve dayanıklılığa sahip olma firsatına sahiptir. Ayrıca hız, çeviklik, reaksiyon süresi, denge, koordinasyon ile temel hareket becerilerinin geliştirilmesi beden eğitimi dersleriyle sağlanabilir (Glickman, Parker, Sim, Cook ve Miller, 2012).

Voleybol, en yüksek derecede motorik özellikleri gerektiren bir spordur (Borràs, Balius, Drobnic ve Galilea, 2011; Marques vd., 2004). Bunun dışında voleybol temel hareketler, kuvvet, hız ve koordinasyonun doğru şekilde kullanılmasını gerektirir (Fontani, Lodi, Felici, Migliorini ve Corradeschi, 2006). Voleybol çabukluk, güç, hareketlilik, esneklik, dayanıklılık ve zıplamaya dayanan, yüksek tempoya sahip dinamiklik gösteren ve fiziksel bir yönü olan oyundur (Erhan, 1995). Ülkemizde voleybola yönelik ilgi 1919'larda başlamıştır. Selim Sırrı 
Tarcan'ın yetiştirmiş olduğu ilk Beden eğitimi öğretmenleri, voleybol branşının okullarda altyapısının oluşmasını sağlamıştır. 1924-1948 yılları arasında bölgesel voleybol şampiyonaları, 1948-1970 yılları arasında Türkiye Voleybol Şampiyonası organize edilmiştir. Deplasmanlı Voleybol Ligleri ise erkeklerde 1970-1971 sezonu, kadınlarda 1984-1985 sezonu itibariyle düzenlenmeye başlanmıştır (TVF, 2020).

Yedi ve on üç yaşları arasında, kızlar ve erkekler aynı uzama oranlarına sahiptir. On üç yaşından sonra, kızların uzaması yavaşlar, ancak erkekler hızlanır. Daha sonrasında bu fark erkeklerin lehine ortaya çıkmaya başlar. Yedi-on sekiz yaş aralığındaki boy uzaması, kızlar için ortalama 40,6 cm iken erkekler için 53,1 cm'dir. Somatik yönlü diğer gelişim parametreleri; oturma yüksekliği, bacakların uzunluğu, kolların uzunluğu, omuzların genişliği ve bikondiler genişlik gibi ölçümlerin benzerlik gösterdiği ortaya çıkmaktadır. On üç-on dört yaş sonrası, erkekler kızlara nazaran daha belirgin fiziksel gelişime sahiptir (Yılmaz, 1999).

Öğrenciler ortaokula başlarken veya devam ederken orta ve yüksek derecede olumlu tutum sergilerler (Colquitt, Walker, Langdon, McCollum ve Pomazal, 2012; Hünük ve Demirhan, 2010; Scrabis-Fletcher, Rasmussen ve Silverman, 2016; Subramaniam ve Silverman, 2007) ve beden eğitimini sevme eğilimindedirler (Ryan, Fleming ve Maina, 2003). Öğrencilerin ilerleyen yaşlarda bu tutumlarının azalması söz konusudur. Kızların tutumlarının erkeklerinkinden daha hızlı bir şekilde azalma eğilimi vardır. Ergenliğin başlamasıyla beraber, öğrencilerin yaşa bağlı olarak olumlu tutumlarının azalması ve diğer okul derslerinde düşüşler yaşaması öngörülmektedir (Kim, Schwartz, Capella ve Seidman, 2014). Çelen (2012), voleybol ünitesini kullanarak ve Spor Eğitim Modeli'ni uygulayarak yaptığı çalışmada öğrencilerin tutumlarının olumlu yönde geliştiğini tespit etmiştir. Mirzeoğlu (2014) ise voleybol ünitesiyle üç öğretim modeline yönelik gerçekleştirdiği çalışmada tüm grupların tutum puanlarının düştüğünü belirlemiştir.

Sosyo profesyonel faaliyetlerin ve okul eğitiminin yoğunlaşmasıyla bu modellerde homojenleşme yönünde bir değişim olmakta; kadınların voleybol, hentbol ve basketbol gibi takım sporlarına artan katılımları dikkat çekmektedir (Pociello, 1997). Diğer bir çalışmada kadınların futbol ve basketbol gibi karşılıklı temas gerektiren sporlardan uzak durdukları, voleybolu daha çok tercih ettikleri saptanmıştır (Dursun, 1996). Ortaokul öğrencilerinin voleybol ile ergenlik döneminde karşılaştıkları ve beden eğitimi dersi aracılığıyla voleybola karş1 ilk tepkilerinin oluşmaya başladığ düşünülmektedir. Olumlu yönde tutum geliştiren öğrenciler voleybol yönelik konularda derse daha istekli katılırlar, okul spor faaliyetlerindeki voleybol maçlarında aktif olarak yer alırlar, voleybolla ilgili haberleri içtenlikle takip ederler, herhangi bir takımda voleybol oyuncusu olurlar veya herhangi bir voleybol kulübünün taraftarı olabilir. Ortaokul dönemindeki öğrencilerin; voleybola ilişkin tutumlarının oluşumunda, bu dönemin önemli olduğu söylenebilir. Bu nedenle ortaokul öğrencilerinin tutumlarının tespit edilerek ölçülmesi gerekmektedir. Literatür açısından değerlendirildiğinde, Mirzeoğlu'nun (2000) Beden Eğitimi ve Spor Yüksekokulu öğrencilerine yönelik ve 28 maddeden oluşan bir "voleybol dersi tutum ölçeği” geliştirdiği görülmektedir. Alan yazında diğer yaş grupları için geliştirilmiş ölçeklere rastlanılmamıştır. Ortaokul öğrencilerinin voleybola ilişkin tutumlarını ölçmek amacıyla ve çok yönlü gelişim (bilişsel, duyuşsal ve psikomotor) alanına yönelik bir ölçeğe ihtiyaç olduğu söylenebilir. Bu araştırmanın amacı ortaokul öğrencilerinin voleybol branşına ilişkin tutumlarını saptamak üzere voleybol ile ilgili bir tutum ölçeği geliştirmektir. 


\section{METOT}

\section{Araştırmanın Modeli}

$\mathrm{Bu}$ araştırma karma yöntem araştırmalarından keşfedici desenle yapılmıştır. Creswell, (2008) karma yöntem çalışmalarının, nitel ve nicel çalışma yöntemlerinin beraber yahutta karıştırılarak uygulanmasının, araştırmanın problemi ve sorularını daha anlaşılır kılacağı görüşündedir. Voleybola yönelik bir tutum ölçeğinin geliştirilmesine yönelik bu çalışmada, genel tarama modeli kullanılmıştır. Tarama modeli yaklaşımı, geçmişte veya bulunduğumuz zaman diliminde var olanı olduğu gibi betimlemeye çalışır (Büyüköztürk, 2009).

\section{Araştırma Grubu}

Çalışma 2014-2015 öğretim y1lında Malatya İl Milli Eğitim Müdürlüğü’ne bağlı 6 farklı ortaokuldaki 600 ortaokul öğrencisini kapsamaktadır. Ölçme aracına dair uygulama, Malatya ili Battalgazi İlçe Milli Eğitim Müdürlüğü’nden alınan 19/12/2014 tarih ve 6700057 sayılı onay doğrultusunda yapılmıştır. Ayrıca bu ölçeğin uygulanması için, yapılan tez çalışması kapsamında "İnönü Üniversitesi" bünyesinde bulunan "Malatya Klinik Araştırmalar Etik Kurulu” ndan 2015/64 sayılı protokol koduyla onay alınmıştır.

\section{Ölçme Aracının Geliştirilmesi}

Voleybol tutum ölçeği taslağı oluşturulma aşamasında alan yazın taranmış ancak daha önceden geliştirilmiş bir voleybol tutum ölçeğine rastlanmamıştır. Bu nedenle voleybol tutum ölçeği aşağıda belirtilen sıra ile geliştirilmiştir:

- Ölçek Taslağının Oluşturulması

- Açıklayıcı Faktör Analizi (AFA)

- Doğrulayıcı Faktör Analizi (DFA)

- Ölçeğin Güvenirliliği

\section{BULGULAR}

\section{Ölçek Taslağının Oluşturulması}

30 ortaokul öğrencisine voleybol ile ilgili komposizyon yazdırılmıştır. Bu kompozisyonlar ve alan yazındaki kaynaklar (Tavşancıl, 2002; Tezbaşaran, 1997) göz önünde tutularak madde havuzu oluşturulmuştur. Madde havuzundaki sorular bilişsel duyuşsal ve psikomotor olmak üzere üç gelişim alanına dönük olarak düzenlenmiş ve 60 maddelik ölçek taslağ 1 oluşturulmuştur. 60 maddelik ölçek taslağ 1 alanında uzman 8 öğretim üyesine gösterilmiş ve öğretim elemanlarının görüşleri doğrultusunda düzenlemeler yapılmıştır. Uzmanlar 10 yıl süresince voleybol derslerini aktif olarak yürüten ve ölçme değerlendirme konusunda bilgi donanımına sahip, çeşitli düzeylerde çalışmaları bulunan kişilerden oluşmaktadır. Son düzenlemeler ile 10 olumsuz ve 26 olumlu olmak üzere 36 maddelik ölçek taslağı likert tipi ölçek olacak şekilde son şeklini almıştır.

\section{Açıklayıcı Faktör Analizi (AFA)}

Ölçek taslağı 6 farklı ortaokulda 600 öğrenciye uygulanmış ve ölçek taslağını eksiksiz ve hatasız dolduran 277'si kız ve 251'i erkek toplam 528 öğrencinin formu bilgisayar programına yüklenmiştir (Tablo 1). İlk olarak olumsuz sorular ters çevrilerek istatistik programına kaydedilmiştir. 
Tablo 1. Ölçek taslağını dolduran öğrencilerin cinsiyetlerine göre dağılımları

\begin{tabular}{cccccc}
\hline Cinsiyetler & 5.sınıf & 6.sınıf & 7.sınıf & 8.sınıf & Toplam ve Yüzde \\
\hline Kız & 20 kişi & 83 kişi & 50 kişi & 124 kişi & 277 kişi- $\% 52,5$ \\
Erkek & 13 kişi & 89 kişi & 38 kişi & 111 kişi & 251 kişi- $\% 47,5$ \\
$\begin{array}{c}\text { Toplam ve } \\
\text { Yüzde }\end{array}$ & 33 kişi- \%6,3 & 172 kişi-\%32,6 & 88 kişi- $\% 16,6$ & 235 kişi-\%44,5 & 528 kişi- $\% 100$ \\
\hline
\end{tabular}

Kayıt altına alınan verileri test etmek amacıyla Açıklayıcı (AFA) ve Doğrulayıcı Faktör Analizi (DFA) yöntemi uygulanmıştır. Elde edilen verilerin Açıklayıcı faktör analizi açısından uygunluğuna karar vermek maksadıyla başvurulan Kaiser-Meyer-Olkin (KMO) puanı 0,96 ve Bartlett Test neticesi anlamlı $(\mathrm{p}<0,01)$ bulunmuş, verilerin AFA için uygun ve yeterli olduğu görülmüştür (Bayram, 2004). Analizde maddeler tek faktörde toplanmış ve faktör yük değeri 0,50 ve üzerinde olan 18 madde göz önünde bulundurulmuştur. Seçilen maddelerin faktör yük değerleri, 0,54 ile 0,74 arasındadır (Tablo 2). Tek faktörün açıkladığı varyans \%44,97'dir. Büyüköztürk (2009), tek boyutlu ölçekler için açıklanan varyansın en az \%30'luk bir oranda bulunmasını ön görmüştür. Madde toplam korelasyonuna bakıldığında ise maddelerin 0,48 ile 0,69 arasında korelasyon katsayısına sahip oldukları görülmüştür.

Tablo 2. Voleybol tutum ölçeğinin açıklayıcı faktör analizi sonuçları

\begin{tabular}{|c|c|c|c|c|}
\hline Madde Sayısı & $\begin{array}{c}\text { Madde } \\
\text { Numaraları } \\
\end{array}$ & $\begin{array}{l}\text { Temel Bileşenler Analizi } \\
\text { 1. Faktör Yük Değerleri }\end{array}$ & $\begin{array}{l}\text { Madde- Toplam } \\
\text { Korelasyonu (r) }\end{array}$ & A. Ort. \\
\hline 1 & Madde 1 & 0,675 & 0,631 & 3,60 \\
\hline 2 & Madde 4 & 0,591 & 0,550 & 3,54 \\
\hline 3 & Madde 5 & 0,691 & 0,641 & 3,69 \\
\hline 4 & Madde 6 & 0,721 & 0,664 & 3,49 \\
\hline 5 & Madde 7 & 0,664 & 0,617 & 3,48 \\
\hline 6 & Madde 9 & 0,612 & 0,563 & 3,42 \\
\hline 7 & Madde 10 & 0,744 & 0,698 & 3,58 \\
\hline 8 & Madde 11 & 0,660 & 0,609 & 3,44 \\
\hline 9 & Madde 13 & 0,544 & 0,488 & 3,39 \\
\hline 10 & Madde 15 & 0,699 & 0,647 & 3,61 \\
\hline 11 & Madde 17 & 0,704 & 0,663 & 3,89 \\
\hline 12 & Madde 20 & 0,638 & 0,582 & 3,52 \\
\hline 13 & Madde 21 & 0,629 & 0,583 & 3,87 \\
\hline 14 & Madde 25 & 0,618 & 0,554 & 3,60 \\
\hline 15 & Madde 26 & 0,741 & 0,696 & 3,54 \\
\hline 16 & Madde 27 & 0,743 & 0,695 & 3,60 \\
\hline 17 & Madde 31 & 0,645 & 0,601 & 3,72 \\
\hline 18 & Madde 33 & 0,724 & 0,674 & 3,66 \\
\hline
\end{tabular}

\section{Doğrulayıcı Faktör Analizi (DFA)}

AFA neticesinde ölçekte bulunan 18 adet madde, Doğrulayıcı Faktör Analizi (DFA) yapılmak üzere Lisrel 8.8 paket programına yüklenmiştir. İlk önce En Çok Olabilirlik Yöntemi'ne (Maximum Likelihood) yönelik path analizi gerçekleştirilmiştir. Analiz neticesinde uyum indekslerini düşürdüğü belirlenen 21 ve 31. maddeler sırasıyla ölçekten çıkartılmıştır. Son olarak, ölçekte 16 madde kalmıştır (Tablo 2-3). Son analiz sonuçlarına bakıldığında (Tablo-3) DFA adına uyum indekslerinin asgari koşulları oluşturduğu görülmüştür (Bayram, 2004; Şimşek, 2007; Yılmaz ve Çelik, 2010). Program kritik kişi sayısını (N) 391,89 göstermiştir. 
Böke, H. ve Güllü, M. (2020). Ortaokul öğrencileri için voleybol tutum ölçeğinin geliştirilmesi. Spor Bilimleri Araştırmalart Dergisi, 5(2), 130-142.

Tablo 3. Voleybol tutum ölçeğinin doğrulayıcı faktör analizi uyum ölçümleri

\begin{tabular}{|c|c|c|}
\hline Uyum Ölçüsü & Değeri & Uyum \\
\hline $\mathrm{X} 2 / \mathrm{sd}$ & $(198,79 / 104=) 1,91$ & İyi uyum \\
\hline $\mathrm{P}$ & 0,00 & İyi uyum \\
\hline RMSEA & 0,042 & İyi uyum \\
\hline Yakın Uyum testi için P değeri & 0,94 & İyi uyum \\
\hline SRMR & 0,030 & İyi uyum \\
\hline NFI & 0,98 & İyi uyum \\
\hline NNFI & 0,99 & İyi uyum \\
\hline CFI & 0,99 & İyi uyum \\
\hline GFI & 0,95 & İyi uyum \\
\hline AGFI & 0,94 & İyi uyum \\
\hline AIC & $\begin{array}{c}\text { Model AIC }=19,99 \\
\text { (Independence AIC }=2153,48 \text { ) }\end{array}$ & $\begin{array}{l}\text { (Karşılaştırılan modelden daha } \\
\text { küçük) model kabul }\end{array}$ \\
\hline CAIC & $\begin{array}{c}\text { Model CAIC }=431,41 \\
\text { (Independence CAIC= } \\
11627,82\end{array}$ & $\begin{array}{l}\text { (Karşılaştırılan modelden daha } \\
\text { küçüik) model kabul }\end{array}$ \\
\hline ECVI & $\begin{array}{c}\mathrm{ECVI}=0,50 \\
\text { (Independence ECVI=21,90) }\end{array}$ & $\begin{array}{c}\text { (Karşılaştırılan modelden daha } \\
\text { küçük) model kabul }\end{array}$ \\
\hline
\end{tabular}

Şekil 1'de ölçekteki maddelerin standartlaştırılmış yük değerlerinin 0,51 ile 0,74 arasında olduğu ve hata katsayılarının 0,46 ile 0,74 arasında olduğu görülmektedir. T-testi açısından bakıldığında, maddelerin tamamının anlamlı $(\mathrm{p}<0,05)$ oldukları belirlenmiştir.

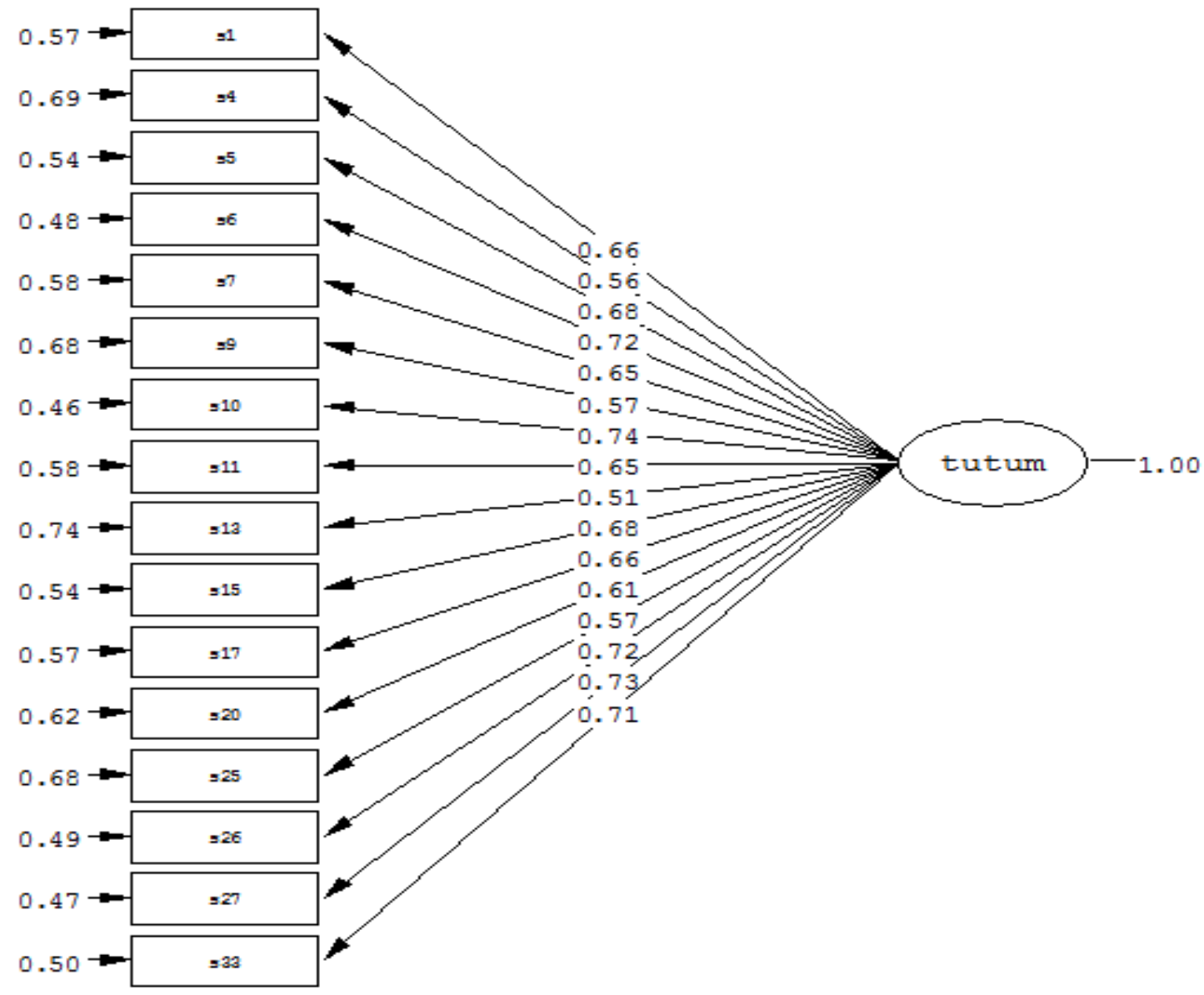

Chi-Square=198.79, df=104, P-value=0.00000, RMSEA=0.042

Şekil 1. Ölçeğin doğrulayıcı faktör analizi standartlaştırılmış sonuçları 
Tablo 4. Voleybol tutum ölçeğinin doğrulayıcı faktör analizi sonuçları

\begin{tabular}{|c|c|c|c|c|c|c|c|c|}
\hline 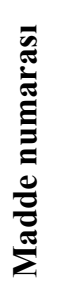 & 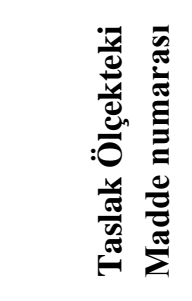 & 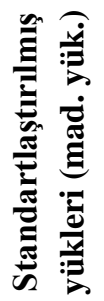 & $\approx$ & 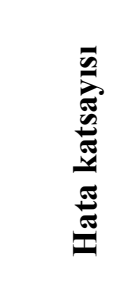 & 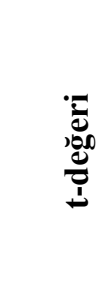 & 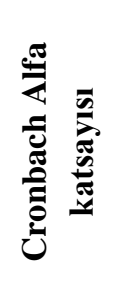 & 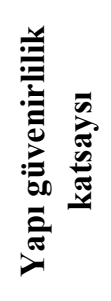 & 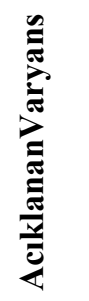 \\
\hline 1 & Madde 1 & 0,66 & 0,43 & 0,57 & 16,53 & \multirow{16}{*}{0,920} & \multirow{16}{*}{0,921} & \multirow{16}{*}{0,43} \\
\hline 2 & Madde 4 & 0,56 & 0,31 & 0,69 & 13,54 & & & \\
\hline 3 & Madde 5 & 0,68 & 0,46 & 0,54 & 17,12 & & & \\
\hline 4 & Madde 6 & 0,72 & 0,51 & 0,48 & 18,76 & & & \\
\hline 5 & Madde 7 & 0,65 & 0,42 & 0,58 & 16,13 & & & \\
\hline 6 & Madde 9 & 0,57 & 0,32 & 0,68 & 13,78 & & & \\
\hline 7 & Madde 10 & 0,74 & 0,54 & 0,46 & 19,24 & & & \\
\hline 8 & Madde 11 & 0,65 & 0,42 & 0,58 & 16,13 & & & \\
\hline 9 & Madde 13 & 0,51 & 0,26 & 0,74 & 12,06 & & & \\
\hline 10 & Madde 15 & 0,68 & 0,46 & 0,54 & 17,20 & & & \\
\hline 11 & Madde 17 & 0,66 & 0,43 & 0,57 & 16,54 & & & \\
\hline 12 & Madde 20 & 0,61 & 0,37 & 0,62 & 15,14 & & & \\
\hline 13 & Madde 25 & 0,57 & 0,32 & 0,68 & 13,73 & & & \\
\hline 14 & Madde 26 & 0,72 & 0,51 & 0,49 & 18,49 & & & \\
\hline 15 & Madde 27 & 0,73 & 0,53 & 0,47 & 18,99 & & & \\
\hline 16 & Madde 33 & 0,71 & 0,50 & 0,50 & 18,21 & & & \\
\hline
\end{tabular}

Bu sonuçlar 1şığında 16 maddesi bulunan ölçek, gerçekleştirilen AFA ve DFA neticesinde birçok uzmana göre geçerliliği sağlanan bir ölçektir (Bayram, 2004; Meydan ve Şeşen, 2011; Şimşek, 2007; Yılmaz ve Çelik, 2010).

\section{Ölçeğin Güvenirliliğgi}

Ölçeğin iç tutarlılık katsayısına (Cronbach Alfa) bakıldığında 0,92 ile iç güvenilirliği sağlanmış bir ölçektir. Uzmanlar, testin güvenirliğinin sağlanması için bu oranın en az 0,70 ve üzeri olması gerektiğini belirtmektedirler (Balc1, 2009; Bayram, 2004; Büyüköztürk, 2009).

\section{TARTIŞMA VE SONUÇ}

Ortaya çıkan bulgulara bakıldığında; 16 maddesi bulunan ölçek, AFA ve DFA neticesinde geçerliliği karşılanmış olan bir ölçektir. Üstelik, ölçeğin iç tutarlılık katsayısı (Cronbach Alfa) .92; yapı güvenirliliği katsayısı. 92; açıklanan varyansı .43 ile güvenilirliği karşılanmış olan bir ölçektir. Öğrencilerin voleybola yönelik tutumlarının bilinmesinin konuların işleniş şekli, antrenmanların uygulanışı ve yeni sporcuların gelişimi açısından katkı sağlayacağı öngörülmektedir. 
Dersin etkinliği ve amaçlarına ulaşılmasına yönelik olarak öğrencilerde gerçekleşen olumlu tutumun, onların derste fiziksel etkinlik ve faaliyetlere gönüllü bir şekilde katılmalarına yardımcı olabileceği bilinmektedir (Silverman ve Scrabis, 2004).

Yapılan araştırmalarda, beden eğitimi ve spor dersine yönelik öğrenci tutumları ölçülmeye çalışılmıştır (Caz ve Göksel, 2016; Güllü vd., 2009; Hekim ve Tokgöz, 2017; Hünük ve Demırhan, 2003; Kangalgil vd., 2006; Kaya Sarıdede, 2018; Kılıç vd., 2018; Özyalvaç, 2010; Şişko ve Demirhan, 2002; Uluışık, 2016; Yağc1, 2012; Zorlu, 2016).

Beden eğitimi ve spor dersinin yanı sıra voleybola yönelik Mirzeoğlu (2000)'nun yapmış olduğu "voleybol dersi tutum ölçeği” geliştirme çalışması bulunmaktadır. İki faktörden oluşan ölçek 14 olumlu ve 14 olumsuz maddeden oluşmakta ve faktör yükleri .35 ten büyük, tutarlılık katsayısı ise (Cronbach Alfa) .88 olarak bulunmuştur. Ölçek puanları voleybola yönelik olumlu bir tutumun söz konusu olduğunu göstermektedir (Mirzeoğlu, 2014).

Beden eğitimi ve spor dersi öğretim programları sürekli olarak güncellenmekte ve nihai olarak şu anda 2018 y1lında güncellenen program uygulanmaktadır (MEB, 2018). Bu doğrultuda öğrencilerce kazandırılmak istenen hedef ve amaçlara yönelik ders etkinliklerinin zenginleştirilmesi ve öğrenci odaklı olması gerekmektedir. Böylelikle, yeni öğretim programlarına yönelik olarak takım sporları denildiğinde akla ilk gelenlerden voleybol konusunun öğrenci tutumları açısından ölçülmeye muhtaç olduğu söylenebilir.

$\mathrm{Bu}$ çalışmada geliştirilen voleybol tutum ölçeğinin, voleybol branşı için öğrencilerin tutumlarını ölçen, geçerli ve aynı zamanda güvenilir bir ölçme aracı olduğu görülmektedir. Öğretmenler, araştırmacılar, antrenörler ve paydaşlar voleybola yönelik tutumla alakalı yapacakları çalışmalarda geçerli ve güvenilir bir ölçme aracı olan voleybol tutum ölçeğini kullanabilir.

Ortaokul öğrencilerine dönük geliştirilen voleybol tutum ölçeği geçerli ve aynı zamanda güvenilir bir ölçektir. Son hali ile ölçek olumlu 16 maddeden meydana gelmektedir. Ölçek Likert tipinde 5'li dereceleme türündedir. Olumlu maddeler; "Tamamen katılmıyorum (1), Katılmıyorum (2), Kararsızım (3), Katılıyorum (4) ve Tamamen katılıyorum (5)" şeklinde puanlanırken olumsuz maddeler; "Tamamen katılmıyorum (5), Katılmıyorum (4), Kararsızım (3), Katılıyorum (2) ve Tamamen katılıyorum (1)" şeklinde puanlanmıştır. Ölçeğin puanlanmasında alınacak en düşük puan 16 iken en yüksek puan 80'dir. 


\section{KAYNAKLAR}

Aicinena, S. (1991). The teacher and student attitudes toward physical education. Physical Educator, 48(1), $28-$ 33.

Akalın, U. (1995). Motiveli sıçrama. Voleybol Bilim ve Teknoloji Dergisi, 4, 27-29.

Balc1, A. (2009). Sosyal bilimlerde araştırma (7. baskı). Ankara: Pegem A Yayınevi.

Bayram, N. (2004). Sosyal bilimlerde SPSS ile veri analizi. Bursa: Ezgi Kitabevi.

Borràs, X., Balius, X., Drobnic, F. \& Galilea, P. (2011). Vertical jump assessment on volleyball: A Follow-up of three seasons of a high-level volleyball team. The Journal of Strength \& Conditioning Research, 25(6), 1686-1694. https:// doi: 10.1519/JSC.0b013e3181db9f2e.

Büyüköztürk, Ş. (2009). Sosyal bilimler için veri analizi el kitabı. Ankara: PegemA.

Carlson, T. B. (1994). Why students hate, tolerate, or love gym: A study of attitude formation and associated behaviors in physical education (Doctoral Dissertation). University of Massachusetts, Massachusetts.

Caz, Ç. ve Göksel, A. G. (2016). Anadolu lisesi öğrencilerinin beden eğitimi dersine yönelik tutumlarının incelenmesi. Marmara Üniversitesi Spor Bilimleri Dergisi, 1(1), 1-1. https://doi.org/10.22396/sbd.2016.0.

Çelen, A. (2012). Spor eğitimi modeli ile işlenen voleybol derslerinin öğrencilerin bilişsel, duyuşsal ve psikomotor erişi düzeylerine etkisi. (Doktora tezi). Gazi Üniversitesi, Eğitim Bilimleri Enstitüsü, Beden Eğitimi ve Spor Öğretmenliği Anabilim Dalı, Ankara.

Colquitt, G., Walker, A., Langdon, J., McCollum, S. \& Pomazal, M. (2012). Exploring student attitudes toward physical education and implications for policy. Sport Scientific and Practical Aspects, 9(2), 5-12.

Creswell, J. W. (2008). Educational research: Planning, conducting, and evaluating quantitative and qualitative research (3. edition). Upper Saddle River: Pearson Education, Inc.

Dursun, A. (1996). Çankırı bölgesinin spora olan yatkinlı̆g ve öncelikli spor branşları. (Yüksek lisans tezi), İstanbul Üniversitesi Sağlık Bilimleri Enstitüsü, İstanbul.

Erhan, S. (1995). Elit düzeydeki voleybolcuların fizyolojik özelliklerinin analizi ve mukayesesi. (Yüksek Lisans tezi). İnönü Üniversitesi, Sağlık Bilimler Enstitüsü, Beden Eğitimi ve Spor Anabilim Dalı, Malatya.

Fontani, G., Lodi, L., Felici, A., Migliorini, S. \& Corradeschi, F. (2006). Attention in athletes of high and low experience engaged in different open skill sports. Perceptual and Motor Skills, 102(3), 791-805. https://doi.org/10.2466/PMS.102.3.791-805.

Franzoi, S. L. (2003). Social Psychology. (3. edition). Boston: Mc. Graw Hill.

Glickman, D., Parker, L., Sim, L. J., Cook, H. D. \& Miller, E. A. (2012). Accelerating progress in obesity prevention: Solving the weight of the nation. Washington, DC: The National Academies Press.

Görücü, A. (2007). İlköğretim 7. sinıf beden eğitimi derslerinde işbirliğine dayalı öğrenim destekli çoklu zekâ kuramı uygulamalarınin ögrrencilerin performans, tutum ve ögrenilenlerin kalıcllğına etkisi. (Doktora Tezi). Selçuk Üniversitesi Sosyal Bilimler Enstitüsü. 
Böke, H. ve Güllü, M. (2020). Ortaokul öğrencileri için voleybol tutum ölçeğinin geliştirilmesi. Spor Bilimleri Araştırmaları Dergisi, 5(2), 130-142.

Güllü, M. ve Güçlü, M. (2009). Ortaöğretim öğrencileri için beden eğitimi dersi tutum ölçeği geliştirilmesi. Beden Ĕ̈itimi ve Spor Bilimleri Dergisi, 3(2), 138-151.

Güllü, M., Güçlü, M. ve Arslan, C. (2009). Ortaöğretim öğrencilerinin beden eğitimi dersine ilişkin tutumlarının incelenmesi. Journal of New World Sciences Academy, 4(4), 273-288.

Güvenç, B. (1976). Değerler, tutumlar ve davranışlar. R. Keleş (ed.), Toplum bilimlerinde Araştırma ve Yöntem. Ankara: Türkiye ve Ortadoğu Amme İdaresi Enstitüsü Yayınları.

Hekim, M. ve Tokgöz, M. (2017). Lise öğrencilerinin beden eğitimi ve spor dersine yönelik tutumlarının cinsiyet değişkenine göre incelenmesi (Burdur örneği). Uluslararası Spor Bilimleri Dergisi, Journal of International Sport Sciences, 3(1), 11-16.

Hilgard, E. R., Atkinson, R. C. \& Atkinson, R. L. (1971). Introduction to psyochology (5. edition). New York: Harcourt Broce Jovanovich.

Hünük, D. ve Demirhan, G. (2003). İlköğretim sekizinci sınıf, lise birinci sınıf ve üniversite öğrencilerinin beden eğitimi ve spora ilişkin tutumlarının karşılaştırılması. Spor Bilimleri Dergisi, 14(4), 175-184.

Hünük, D. ve Demirhan, G. (2010). Turkish adolescents' attitudes toward physical education. Perceptual and Motor Skills, 111, 324-332.

Kangalgil, M., Hünük, D. ve Demirhan, G. (2006). İlköğretim, lise ve üniversite öğrencilerinin beden eğitimi ve spora ilişkin tutumlarının karşılaştırılması. Spor Bilimleri Dergisi, 17(2), 48-57.

Katz, D. \& Stotland, E. (1959). A preliminary statement to a theory of attitude structure and change. (Koch, Ed.). New York: Mcgraw-Hill.

Katz, D. (1960). The functional approach to the study of attitudes. Public Opinion Quarterly, 24(2), 163-204. https://doi.org/10.1086/266945.

Kaya Sarıdede, Ş. (2018). Ortaöğretim öğrencilerinin beden ĕgitimi dersine ilişkin tutumlarının incelenmesi (Yüksek Lisans Tezi). İstanbul Gelişim Üniversitesi, Sağlık Bilimleri Enstitüsü, Antrenörlük Eğitimi Anabilim Dali.

Kelman, H. (1958). Compliance, identification, and internalization: Three processes of attitude change. Journal of conflict resolution, 2(1), 51-60. https://doi.org/10.1177/002200275800200106.

Kelman, H. (1961). Processes of opinion change. Public Opinion Quarterly, 25(1), 57-78.

Kılıç, T., Uğurlu, A. ve Cenik, D. (2018). Lise birinci sınıf öğrencilerinin beden eğitimi ve spor eğitimi dersine karşı tutumlarının incelenmesi. Gaziantep Üniversitesi Spor Bilimleri Dergisi, 3(2), 13-23. https://doi.org/10.31680/gaunjss.410742.

Kim, H., Schwartz, K., Capella, E. \& Seidman, E. (2014). Navigating middle grades: Role of social context in middle grade school climate. American Journal of Community Psychology, 54, 28-45 https://doi 10.1007/s10464-014-9659-x.

Klausmeier, H. J., Goodwin, W. L., Prasch, J. \& Goodson, M. R. (1966). Project models: maximizing opportunities for development and experimentation in learning in the schools. Madison, WI: Wisconsin Research And Development Center.

Krech, D. \& Crutchfield, R. S. (1980). Sosyal psikoloji. (E. Güngör, Çev.) (3. baskı). İstanbul: Ötüken Yayın. 
Böke, H. ve Güllü, M. (2020). Ortaokul öğrencileri için voleybol tutum ölçeğinin geliştirilmesi. Spor Bilimleri Araştırmaları Dergisi, 5(2), 130-142.

Marques, M. C., González-Badillo, J. J., Cunha, P., Resende, L., Santos, M. \& Domingos, P. (2004). Changes in strength parameters during twelve competitive weeks in top volleyball athletes. Int J Volley Res, 7, 2328. doi: 10.1007/s10464-014-9659-x.

Milli Eğitim Bakanlığı. (2018). Beden eğitimi ve spor dersi öğretim programı. Ankara: Millî Eğitim Bakanlığı.

Meydan, C. H. ve Şeşen, H. (2011). Yapısal eşitlik modellemesi Amos uygulamaları. Ankara: Detay Yayıncılık.

Mirzeoğlu, D. (2000). Voleybol dersindeki davranışların öğreniminde, yapılanmacı öğrenme etkinliklerinin ögrenci erişisi düzeyine etkisi (Doktora tezi). Abant İzzet Baysal Üniversitesi, Sosyal Bilimler Enstitüsü.

Mirzeoğlu, A. D. (2014). The effects of peer teaching on the university students achievements in cognitive, affective, psychomotor domains and game performances in volleyball courses. Educational Research and Reviews, 9(9), 262-271. https://doi.org/10.5897/err2013.1690.

Özyalvaç, N. (2010). Ortaöğretim öğrencilerinin beden ĕgitimi dersine yönelik tutumlarl ile akademik başarı motivasyonlarının incelenmesi (Konya Anadolu Lisesi örneği) (Yüksek Lisans tezi). Selçuk Üniversitesi, Sağlık Bilimleri Enstitüsü, Beden Eğitimi ve Spor Anabilim Dalı.

Pociello, C. (1997). Les cultures sportives. Paris: P.U.F.

Ryan, S., Fleming, D. \& Maina, M. (2003). Attitudes of middle school students toward their physical education teachers and classes. Physical Educator, 60(2), 28-42.

Safrit, M. J. \& Wood, T. M. (1995). Introduction to measurement in physical education and excercice science. St. Louis, MO: Mosby.

Scrabis-Fletcher, K., Rasmussen, J. F. \& Silverman, S. (2016). The relationship of practice, attitude, and perception of competence in middle school physical education. Journal of Teaching in Physical Education, 35, 241-250. https://doi.org/10.1123/jtpe.2015-0129.

Silverman, S. \& Scrabis, K. A. (2004). A review of research on instructional theory in physical education 20022003. International Journal of Physical Education, 41(1), 4-12.

Silverman, S. \& Subramaniam, P. R. (1999). Student attitude toward physical education and physical activity: A review of measurement issues and outcomes. Journal of Teaching in Physical Education, 19(1), 97-125. https://doi.org/10.1123/jtpe.19.1.97.

Şimşek, Ö. (2007). Yapısal eşitlik modellemesine giriş. Ankara: Ekinos.

Şişko, M. ve Demirhan, G. (2002). İlköğretim okulları ve liselerde öğrenim gören kız ve erkek öğrencilerin beden eğitimi ve spor dersine ilişkin tutumları. Hacettepe Üniversitesi Eğitim Fakültesi Dergisi, 23, 205-210.

Smith, M. B., Bruner, J. S. \& White, R. W. (1956). Opinions and personality. New York: Wiley.

Strand, B. \& Scantling, E. (1994). An analysis of secondary student preferences towards physical education. The Physical Educator, 51(3), 119-129.

Subramaniam, P.R. \& Silverman, S. (2007). Middle school students' attitudes toward physical education. Teaching Elementary Physical Educationand Teacher Education, 22, 602-611.

Tavşanc1l, E. (2002). Measurement of attitudes and data analysis with SPSS. Ankara: Nobel Publication Distribution Co.Ltd. 
Böke, H. ve Güllü, M. (2020). Ortaokul öğrencileri için voleybol tutum ölçeğinin geliştirilmesi. Spor Bilimleri Araştırmaları Dergisi, 5(2), 130-142.

Tezbaşaran, A. A. (1997). Likert type scale development guide (2. edition). Ankara: Turkish Psychological Association Publications.

Türkiye Voleybol Federasyonu, (2020). Türkiye'de voleybolun klsa tarihçesi. https://www.tvf.org.tr/tarihce/\#: :text.

Uğraş, S. ve Serbes, Ş. (2019). Beden eğitimi dersi mutluluk düzeyi ölçeği geçerlik ve güvenilirlik çalışması. Journal of Global Sport and Education Research, 2(2), 1-10.

Uluışı, V. (2016). Ortaöğretim öğrencilerinin beden eğitimi dersi ne yönelik tutumlarının sınıf ve cinsiyet değişkenlerine göre incelenmesi. Uluslararası Multidisipliner Akademik Araştırmalar Dergisi, 2(3), 4553.

Yağc1, İ. (2012). Ortaöğretim öğrencilerinin beden ĕgitimi dersine ilişkin tutumlarının incelenmesi (Afyonkarahisar İli Örneği) (Yüksek Lisans tezi). Afyon Kocatepe Üniversitesi, Sağlık Bilimleri Enstitüsü / Beden Eğitimi ve Spor Anabilim Dalı.

Yılmaz, F. (1999). Futbol takımları alt yapılarının teknik ve motorik beceri yönünden karşılaştırılması (Yüksek Lisans). Sakarya Üniversitesi, Sosyal Bilimler Enstitüsü.

Yılmaz, V. ve Çelik, E. (2010). Lisrel ile yapısal eşitlik modellemesi I. Ankara: Pegem Akademi Yayıncılık.

Zorlu, A. (2016). Ortaöğretim öğrencilerinin beden eğitimi dersine yönelik tutumlarinin sinıf ve cinsiyet değişkenlerine göre incelenmesi (Kumluca ilçesi örneği). Uluslararası Spor Bilimleri Dergisi, 2(2), 2027. 


\section{EK. Voleybol Tutum Ölçeği}

\begin{tabular}{|c|l|c|c|c|c|}
\hline \multicolumn{1}{|c|}{ VOLEYBOL TUTUM ÖLÇEĞi } & & & \\
& & \multicolumn{1}{|c|}{} & & \\
& & &
\end{tabular}

Bu eser Creative Commons Atıf-GayriTicari 4.0 Uluslararası Lisansı ile lisanslanmıştır. 